\title{
Parental Concerns in Facilitating Children's Physical Activity Participation in Hong Kong 香港家長於促進學童參與體育活動之考慮因素
}

\author{
Bonnie On Hei PANG Amy Sau Ching HA \\ Department of Sports Science and Physical Education, \\ The Chinese University of Hong Kong, HONG KONG \\ 彭安熙夏秀禎 \\ 香港中文大學體育運動科學系
}

\begin{abstract}
This study examines the parental concerns in facilitating their children's physical activity participation in Hong Kong. By adopting a qualitative approach, 22 parents (10 fathers and 12 mothers), randomly chosen from in a larger study examining 802 (aged 9 to 16) children's physical activity engagement, were invited for a semi-structured interview. It is believed that these parents could represent the typicality of Hong Kong parents in increasing our understanding of the study's focus. Interview data were analyzed by using an open coding system to identify meaningful pieces of information within the comprehensive text segment (Tesch, 1990). Three themes emerged from the interview data and results in relation to Confucianism showed that parental long working hours, safety issues and over emphasize in children's academic pursuits were found to be their major concerns in facilitating children's further engagement in physical activities. Specifically, fathers and mothers were found to differ in their safety concerns for their children's physical activity involvement. Future interventions aiming at solving the suggested parental concerns could increase children's physical activity participation.
\end{abstract}

Key words: parental concerns, children, Confucianism

\section{摘 要}

採用質化研究之方法, 本研究旨在探討二十二名香港家長於促進學童參與體育活動的考慮因素。研究發現考慮因素包括： 家長的工作時間、家長對學童參與體育活動的安全性及家長過份重視學業成績。研究結果建議, 為要進一步促進學童參與體育活 動, 必須透過有效解決家長對學童於參予體育活動的考慮因素。(一) 加強家長對帶有危險性的運動的知識 (二) 政府及學校團 體應增加對家庭運動的支持 (三) 透過工作坊, 讓家長了解學業與運動並存對學童身心發展的重要性。

\section{Introduction}

\section{Insufficient Physical Activity in Hong Kong Children and its Consequences}

Despite the weak evidence in the casual relationships between physical activity and health status in children, relevant data indicates that physical activity can result in some health benefits for children and adolescents. Physical activity among adolescents is consistently associated with higher levels of self-esteem and self-concept (Armstrong \& Welsman, 1997; Chan \& Michlei, 1998; Taylor et al. 2004; Trembly, Inman, \& Willms, 2000). Lower levels of anxiety and stress were found in adolescents who engaged in regular exercise (Paluska \& Schwenk, 2000). Though children generally adopt a higher physical activity 
level than adults, its level begin to decline as children approach their adolescence and continue to decline as they reach their adulthood (Armstrong \& Welsman, 1997).

Studies indicated that Hong Kong children's health status is at risk due to their low physical activity rate. Cardio-respiratory endurance, muscular speed, power, and muscular strength and endurance of Hong Kong school children are not as good as their counterparts in the Mainland China (Hong, Chan \& Li, 1998) and the level of childhood obesity in Hong Kong has been increasing over the years (F. H. Fu, Nie, \& Tong, 2004; F. J. Fu \& Hao, 2002; Hui, 2004). When examined the weekend activity pattern of Hong Kong children, research (Johns, Morris, Wong \& Ha, 2003) revealed that more than $50 \%$ of them failed to meet the standard of "accumulating at least 30 minutes of moderate intensity physical activity on most and preferably all days of the week" (ACSM, 2000). While at school, physical education provides children with a variety of educational and psychomotor experiences, the limited amount of time in the curriculum (Johns, Ha \& Macfarlane, 2001) is insufficient for promoting health or fitness. In particular, girls had lower participation than boys (Ha, 2006; Linder, 1998). With such findings, Hong Kong children are not receiving the benefits of physical activity either at school or at home settings.

\section{Parental Socialization in Children's Physical Activity Participation}

Parents have well been identified as one of the major socialization agents in children's development, especially during childhood years (Fredricks \& Eccles, 2005; Sallis, Prochaska \& Taylor, 2000; Shakib \& Dunbar, 2004). This is because a large proportion of children's free time prior to adolescence is spent within the family context and parents could play a variety of roles including coaches, chauffeur, financier and gatekeepers (Biddle \& Goudas, 1996; Fredricks \& Eccles, 2004; Hoefer, Mckenzie, Sallis, Marshall, \& Conway, 2001; Weiss \& Hayashi, 1995). Research suggested that parents exert considerable influence in children's physical activity participation in a variety of ways: (a) by being a role model either as a coach or by participating in athletics themselves; (b) by interpreting their children's experience and giving them messages about their athletic ability and the value of participating in sport; (c) by providing emotional support and positive athletic experiences for their children's involvement in sport (Fredricks \& Eccles, 2005). Recent studies of youth sport participation have also found out that parents can mediate children's motivation in sport and physical education (Loucaides \& Chedzoy, 2005; Sallis, Prochaska \& Taylor, 2000; Welk, Wood \& Morss, 2003). The mechanisms can be either directly by providing a supportive, nurturing environment, or indirectly through modeling, or more likely, an interaction of the two.

\section{Reasons Accounting for the Insufficient PA in children-a Hong Kong Family Perspective}

In understanding the home settings in promoting physical activity, a sociocultural perspective in examining the construction of Chinese ideology is needed. Generated by Confucianism, Chinese parents were found to stress great importance on hard work in school achievement (Chao \& Sue, 1996) and parents in Hong Kong in particular, tend to be practically oriented, wanting their children to be successful in getting a well-paid job by obtaining a place in an exemplary university (Chan, 1996). With the Hong Kong Certificate of Examination (HKCEE) and Hong Kong Advanced Level Examination (HKALE) being the highlight in the education milieu, as students move into their senior forms, they would rather place emphasis on their future plans and focus on subjects which are most important for reaching academic success (Cheung, 2003; Hong, Chan \& Li, 1998; Pang, 2007) other than physical activity.

Apart from stressing academic performance, Confucian principles attribute authority to parents, and in particular to fathers who are regarded as leader in the family to which family members should be obedient and respectful (Johns \& Vertinsky, 2006). Therefore children being subordinated to their parents' supervision must conform to the culture values and practice. This obedience is further accentuated between boys and girls within the male dominant family. According to Slote and Devos (1998), the rights of women and children were minimal and therefore children, especially girls, are believed to enjoy the least opportunities in their activities development. Children, especially for girls, suggested that a lack of family support is one of the major constraints for not doing more exercise (Ha, 2006). With the influence on Confucianism within the family, the continuous decrease in physical activity challenges the quality of life and health of Hong Kong children. 


\section{Purpose}

Most of the published researches on the relations between parents and children in physical activity participation have been based on the study of populations predominately from Western cultures and from a quantitative approach (Brustad, 1996; Fredricks \& Eccles, 2005; Greendorfer, 2001). Consequently there remains a dearth of research examining qualitatively the parental concerns in their children's physical activity participation in a Chinese culture setting. Though studies in Hong Kong have concluded that parents place high expectations in children's studies and forbid them to participate in physical activities, not much work has identify the possibility of gender differences among the parental concerns. Therefore this study intends to fill the gaps in addressing a comprehensive set of parental concerns in children's sport participation and most importantly, to identify the possibility of gender differences within their concerns. For children to develop active patterns of living it is important to fully understand the sociocultural context in which parents provide for their children before specific intervention programmes could be tailor-made to promote physical activity participation in Hong Kong families. This study defines physical activity as "any bodily movement that is produced by the contraction of skeletal muscle and that substantially increases energy expenditure" (American College of Sports Medicine, 2006). The participants in this study used "sport", "Physical Education" and "physical activity" interchangeably.

\section{Methodology}

By adopting a qualitative approach, this study was conducted within the context of a larger study examining the physical activity engagement of 802 children, aged between 9 and 16. Twenty-two parents (10 fathers and 12 mothers), randomly chosen from the children's family in the larger study, were invited for a semi-structured interview concerning their roles in their children's physical activity participation. A letter of informed consent was delivered to the school principal after an initial introduction and request to conduct the study. Additionally, a written informed consent was delivered by the children to their parents. All participants were told that their involvement in the study was voluntary and that they could withdraw at any time without prejudice.
Parents were then contacted by phone to arrange a mutually convenient time for the interview. In all cases, the interviews were conducted by one consistent interviewer through the phone. The interviewer had established rapport with parents at the start of the interview. Interviews which lasted about half an hour in duration were conducted using a semi-structured interview schedule that enabled further probing of responses. Interview questions were modeled on the survey conducted by Booth, Macaskill, Phongsavan, McLellan and Okely (1997) and Brannen (1994).The interview schedule was trialed with one parent in Cantonese, whom was known to the interviewer prior to commencing the study interviews. All interviews were written down in Chinese and transcribed verbatim into English after each of the interview. In addition, results were sent to each interviewer within a week after the telephone interview for judging the accuracy and credibility of the data collected. Confidentiality was stressed and parents were encouraged to express their views as honestly as possible. An open coding system was used to identify meaningful pieces of information that formed comprehensive text segments (Tesch, 1990). The segments with similar meaning were collected and tagged so that the interviewees and their responses could be identified according to similar topics (Miles \& Huberman, 1984).

\section{Results and Discussion}

Three themes emerged during the interview and results showed that parental work commitments, safety issues and their generally high expectation of children's academic success were the major concerns for facilitating children's physical activity participation. Specifically, this study tries to identify the possibility of gender differences within the parental concerns.

Parental long working hours result in the limited time available to cater the needs of their children in their physical activity participation. Both fathers and mothers revealed that they could not afford extra time with their children in physical activity during weekdays because of their intense working hours. Parents, in their hectic schedule could spare time only on weekends for family gatherings however time were mostly spent on watching movies and televisions or dining out and thus creating a sedentary lifestyle for their children and themselves (Johns, Morris, Wong \& Ha, 2003; Johns and Ha, 1999; Ha, 2006). Exemplified by a father, "Both of us need 
to work six days a week, well...we're not rich and we must work for the money for the family. Sometimes we would go out with the kids on Sundays and we usually go shopping or dining out". Also noted by a mother, "We don't go exercising much often, not after work or on weekends because it seems that we don't have much energy to workout anymore after so many days of work. Sometimes the kids would ask for playing badminton, and I'd play for a while but this isn't what we like to do. Besides, there isn't much place for us to play, every where is people on Sundays, even parks and badminton courts". It is therefore not difficult to understand that children were not able to attain moderate-to-vigorous physical activity levels at home and on weekends.

Hong Kong, renowned for its competitive market economy focuses on individuals' earning power in determination of their success, has facilitated the long working hours of parents. In the past, father's role was dominantly the breadwinner while mother was the housekeeper. However, interview results suggested that both fathers and mothers nowadays are responsible for earning the family's livelihood. Though the results in the changing role of mothers may not generalize to every household in Hong Kong, it is believed that earning money for the betterment of the family has a high priority and time for leisure is being sacrificed for this purpose. While encouraging parents to spend more time with their children in physical activity seems to be difficult, other suggestive measures regarding the effective use of time and the surrounding environment may help rectifying the problem. Parents could encourage children walking to and from school with neighborhood companions instead of taking transportations. During weekends, parents could organize family activities in country parks which provide much open space and air for their physical health.

In terms of safety concerns, all parents consciously discourage their children to participate in potentially dangerous physical activities and believe that their children are too young to make right decisions for themselves. Specifically, mothers and fathers differ in their safety perception. Mothers typically focus on the safety of the environment in their children's sport while fathers focus on the types of sport that their sons or daughters should or should not participate. Exemplified by a mother, "I think playing ice-hockey is very dangerous, people are bumping together and it's so easy to get hurt. Being the mother, I think I'm responsible for his safety and I couldn't bare the consequence if he gets hurt. Besides, he's still young and is easily influence by friends. I'm not quite sure the background of his friends and I'm afraid he'll become naughty. And sometimes those children in the ice-skating area smokes and say foul language, I don't want him to learn from them". Noted by a father, "Some dangerous activities, like skating, it's not too safe for my girl to play. Children usually can't decide what is dangerous for them. They just play whatever is fun but neglect the importance of safety. For example, I won't let him go climbing hills or rock...it's too dangerous. I've seen quite a lot of accidents happened in people climbing, it's definitely not suitable for children, especially girls, it's just not right for her to play such rough sport and Hong Kong don't have much safe climbing places for younger ones and there is a lack of qualified teachers ".

In Chinese families, mothers' roles are to nurture the children while fathers are to teach and discipline (Slote \& DeVos, 1998). In the interviews, mothers focus on ensuring a safe environment for their children in the physical activity context while fathers are responsible in determining what kinds of sport is suitable for their children's gender. The roles of parents nowadays seem distinct and similar with those previously practiced. It is suggested the impact of Confucianism will continue to influence Hong Kong families in their daily practice. Results also showed that when parents are unfamiliar with the sport nature, such as ice-hockey and rock climbing, it is easier for them to forbid children joining potentially dangerous activities.

The findings suggested that parental safety concerns had three dimensions, safety in terms of the type of physical activity, safety in the way how children make decisions and safety in terms of the environment related to children's physical activity. First, to minimize the effect of parental safety concerns in potentially dangerous sport, government bodies could provide more information on their safety precautions through the media. Sport organizations could increase their credibility by ensuing appropriate qualifications in their instructors. Second, in increasing children's sporting opportunities and to minimize the influence of the environmental concerns, schools and government organizations could promote traditional gender stereotyped sport to both parents and children, and to convey the message that boys and girls should be given equal opportunities in various sports. It is understandable that all parents aim to safeguard their children's lives by 
protecting them at all means, but parents should also take into account that suitable room for children to make their own decisions and to make mistakes are necessary process of healthy growth.

Another issue that parents dated as a concern for facilitating their children's physical activity engagement was parents' relatively high expectation of their children's academic success. Both fathers and mothers have commented, "My son is now in the soccer team and he practices for many days a week...he comes back home at $7: 00 \mathrm{pm}$ and I think soccer is distracting him from studying well...I'm so afraid that he'll get hurt and I'm thinking not to let him play anymore", "I usually let him do whatever he wants in sports but if the exam is near, I'd advise him to play less basketball, I think it's better for him to spend more time studying than on playing". Parents prioritized their children's engagement upon their high expectations in academic studies. The sacrifice was often the students' time involvement in physical activities. Results are in agreement with previous findings (Cheung, 2003; Hong, Chan \& Li, 1998; Johns \& Dimmock 1999; Linder, 1999), suggesting that Hong Kong parents, as one of the Confucian cultural heritage, placed great emphasis on children's school achievement (Chao \& Sue, 1996; Chan, 1996) and forbidden their children to join sport. Parents believed that time not spent on studying rather than on physical activities is unwise as these two activities are contradictory in nature. Despite this conclusive finding found in most studies, one father believed that sport is a function of health and is important despite academic concerns, "I'd allow my daughter play sport as I think sport is good for her health, I don't think study and sport intervene with each other. If they don't do sport, it doesn't mean they'll study. I think it's time management more than anything else. Besides, I think it's important to be healthy in order to concentrate in studies". To increase children's physical activity participation, parents should understand that there is no correlation between students' academic achievement and participating in physical activity (Yu, Chan, Cheng, Sung, \& Hau, 2006). Further interventions should focus on educating parents that academic and physical activity are non-conflicting pursuits. Educational programmes could exhibit successful athletes who have also achieved remarkable academic results and children could view them as role models or mentors. It is important for both parents and children to understand that having a health body is the same as important as having good academic results.

\section{Conclusion}

Issues such as parental work commitments, safety issues and high expectations on children's academic success were expressed as the major concerns in children's active lifestyles. Results suggested that fathers and mothers expressed their worries differently in safety issues but not in the other two types of concerns. If physical activities need to be increased for Hong Kong children, the sphere of influence would seem to be with how parents seek more opportunities in the involvement and facilitation in children's physical activities, on solving safety issues in relation to the types of children's physical activity, especially on the different views between fathers and mothers, and with how parents balance their expectations on academic studies with physical activities. Future interventions aiming at solving these parental concerns may improve children's physical activity participation.

Theoretically, though Confucianism may seem convincing in explaining the Chinese culture, we should take cautious in the interpretation as Confucianism is not empirically based and is more like philosophies instead of a theory (Lau \& Yeung, 1996). Hence further scientific examinations should be conducted in explaining the contemporary Chinese society. In addition, due to effective administration, parental interviews were conducted through the phone within a 30 minute session, no faceto-face contact was available and this may affect the comprehensiveness of information. Future qualitative studies could include ethnographic designs and focus group interviews to compensate the flaws and in enriching the data. The results of this study point to the importance of the major impact parents have on the development of active lifestyles in their children. 


\section{References}

American College of Sports Medicine (2000). Guidelines for exercise testing and prescription ( $7^{\text {th }}$ ed.). Philadelphia, PA: Lippincott Williams \& Wilkins.

Armstrong, N., \& Welsman, J. (1997). Young people and physical activity. (pp 212-275). New York: Oxford University Press.

$\mathrm{Au}$, K.F.C. (2006). The perceived influence of socialising agents on Hong Kong youth's entry into sports participation. In D. Johns \& K. Lindner (Eds.), Physical activity and health of Hong Kong youth (pp. 151- 166). Hong Kong: Chinese University Press.

Booth, M.L., Macaskill, P., Phongsavan, P., McLellan, L., \& Okely, T. (1997). NSW Schools Fitness and Physical Activity Survey 1997. Sydney: NSW DSE.

Brannen, J., (1994) Young people, Health and Family Life. Buckingham, UK: OUP.

Biddle, S., \& Goudas, M. (1996). Analysis of children's physical activity and its association with adult encouragement and social cognitive variables. Journal of School Health, 66(2), 75-78.

Brustad, R. J. (1996). Attraction to physical activity in urban schoolchildren: Parental socialization and gender influences. Research Quarterly for Exercise and Sport, 67(3), 316-323.

Chao, R. K., \& Sue, S. (1996). Chinese parental influence and their children's school success: A paradox in the literature on parenting styles. In Lau, S. (Ed.), Growing up the Chinese way. Chinese Child and adolescent development (pp. 93-120). Hong Kong: The Chinese University Press.

Chan, J. (1996). Chinese intelligence. In Bond, M. H. (Eds.), The handbook of Chinese psychology (pp. 93-108). Hong Kong: Oxford University Press.

Chan, K.M., \& Micheli, L.J. (1998). Scholastic and intellectual development and sports. (pp. 76-87). Hong Kong: WHO Collaborating Center for Sports Medicine and Health Promotion, CUHK.
Cheung, R. H. P. (2003). Factors influencing attitudes of Hong Kong secondary school students toward physical education. Journal of Physical Education and Recreation (Hong Kong), 9(2), 71- 78.

Fredricks, J. A., \& Eccles, J. S. (2004). Parental influences on youth involvement in sports. In $\mathrm{R}$. M. Weiss (Ed.), Developmental sport and exercise psychology: A lifespan perspective (pp. 145-164). Morgantown, WV: Fitness Information in Technology.

Fredricks, J. A., \& Eccles, J. S. (2005). Family socialization, gender, and sport motivation and involvement. Journal of Sport and Exercise Psychology, 27, 3-31.

Foucault, M. (1982). The subject and power. In: H. Dreyfus and P. Rabinow (Eds.), Michel Foucault: Beyond Structuralism and Henneneutics. Chicago: University of Chicago Press.

Fu, F. H., Nie, J., \& Tong, T. K. (2004). An overview of health fitness of Hong Kong children and adults in the past 20 years (1984-2004) - part 1. Journal of Exercise Science and Fitness, 2(1), 8-22.

Fu, F. J., \& Hao, X. (2002). Physical development and lifestyle of Hong Kong secondary school students. Preventive medicine, 35, 499-505.

Greendorfer, S. L. (2001). Gender role sterotypes and early childhood socialization. In G. L. Cohen (Eds.), Women in sport. Issues and controversies (2nd ed., pp. 3-23). Oxon Hill, MD: National Association for Girls and Women in Sport.

Ha, A. S. (2006). A report on comparison of children's sport participation and physical activity pattern in Hong Kong and Australia (No. CA11040), Hong Kong, China.

Ha, A.S., \& Pang O.H. (2006). Sport participation and physical activity pattern of Hong Kong children. Paper presented at the meeting of the AIESEP World Congress, Role of Physical Education and Sport in Promoting Physical Activity and Health, Jyvasklya, Finland. 
Hoefer, W. R., Mckenzie, T. L., Sallis, J. F., Marshall, S. J., \& Conway, T. L. (2001). Parental provision of transportation for adolescent physical activity. American Journal of Preventive Medicine, 21(1), 4851.

Hong, Y., Chan, K.M., \& Li, J.X. (1998). Health-related physical fitness of school children in Hong Kong and Mainland China- A comparative analysis. Journal of Comparative Physical Education and Sports, 20(1), 2-10.

Hui, S. (2004). Current Perspectives on Health and Physical Activity in Hong Kong: A Review. Journal of Physical Activity and Health, 1, 56-70.

Johns, D., \& Vertinsky, P. (2006). The influence of physical, cultural and social environments on helthrelated activity. In D. Johns \& K. Lindner (Eds.), Physical activity and health of Hong Hong youth (pp. 182-196). Hong Kong: Chinese University Press.

Johns, D., Ha, A.S., \& Macfarlane, D. J. (2001). Raising Activity Levels: A Multi-Dimensional Analysis of Curriculum Change. Sport, Education and Society Journal. 6(2), 199-210.

Johns, D. P., Morris, J.G., Wong, S.H.S. \& Ha, A.S. (2003). Weekend discretionary activity patterns of Hong Kong youth. Journal of Sports Sciences, 21(4), 278.

Johns, D. P., \& Dimmock, C. (1999). The marginalization of physical education: impoverished curriculum policy and practice in Hong Kong. Journal of Education Policy, 14(4), 363-384.

Johns, D., \& Ha, A. S. (1999). Home and Recess Physical Activity Behaviours of Hong Kong Children. Research Quarterly for Exercise and Sport, 70(3), 319-323.

Lau, S. \& Yeung, P. P. W. (1996). Understanding Chinese child development: The role of culture in socialization. In Lau, S. (Eds.), Growing up the Chinese way. Chinese Child and adolescent development (pp. 29-44). Hong Kong: The Chinese University Press.
Lindner, K. J. (1999). Sport participation and perceived academic performance of school children and youth. Pediatric Exercise Science, 11(2), 129-143.

Lindner, K. J. (1998). Sport and activity participation of Hong Kong school children and youth-part 1. The Hong Kong Journal of Sports Medicine and Sports Science, 16-28.

Miles, M. \& Hubermanm, A. (1984). Qualitative data analysis: an expanded source-book. Newbury Park, CA: Sage.

Pang, O.H. (2007). Parental beliefs and children's moderate-to-vigorous physical activity participation in Hong Kong. Poster session presented at the meeting of the American College of Sports Medicine: annual meeting, New Orleans, USA.

Paluska, S.A., \& Schwenk, T.L. (2000). Physical activity and mental health: current concepts. Sports Medicine, 29(3), 167-180.

Sallis, J., Prochaska, J., \& Taylor, W. (2000). A review of correlates of physical activity of children and adolescents. Medicine and Science in Sports and Exercise, 32, 963-975.

Slote, W. H. (1998). Pscyhocultural dynamics within the Confucian family. In. Slote, W. H. \& Devos, G. A. (Eds), Confucianism and the Family (pp. 38). USA: State University of New York.

Shakib, S., \& Dunbar, M. D. (2004). How high school athletes talk about maternal and parental sporting experiences. International Review for the Sociology of Sport, 39(3), 275-299.

Talyor, M. K., Pietrobon, R., Pan, D., Huff, M., \& Higgins, L.D.(2004). Healthy people 2010 physical activity guidelines and psychological symptoms: evidence from a large nationwide database. Journal of Physical Activity and Health, 1, 114-130. 
Tesch, R. (1990). Qualitative research and analysis types and software tools. New York: Falmer.

Tremblay, M.S., Inman, J.W., \& Willms, J.D. (2000). The relationship between physical activity, self-esteem and academic achievement in 12-year-old children. Pediatric Exercise Science, 12(3), 312-323.

Weiss, R. M., \& Hayashi, C. T. (1995). All in the family: Parent-child influences in competitive youth gymnastics. Pediatric exercise science, 7, 36-48.

Yu, C., Chan, S., Cheng, F., Sung, R., \& Hau, K. T. (2006). Are physical activity and academic performance compatible? Academic achievement, conduct, physical activity and self-esteem of Hong Kong Chinese primary school children. Educational Studies, 32(4), 331-341.

\section{Correspondence:}

Contact person Ms Bonnie Pang On Hei 彭安熙

Telephone

(852) 26096098

Kwok Sports Building,

Department of Sports Science and

Mailing Address:

Physical Education,

The Chinese University of Hong

Kong, Shatin, N.T.,

Hong Kong.

Fax:

(852) 26035781

Email: bonniepangsspe@cuhk.edu.hk 